\title{
Estado e políticas sociais: a hegemonia burguesa e as formas contemporâneas de dominação
}

\author{
Ivete Simionatto \\ Universidade Federal de Santa Catarina (UFSC)
}

\author{
Carolina Rodrigues Costa \\ Universidade Federal de Santa Catarina (UFSC)
}

\section{Estado e políticas sociais: a hegemonia burguesa e as formas contemporâneas de dominação}

Resumo: A partir de uma pesquisa teórica, o artigo reconstrói as categorias gramscianas hegemonia, aparelhos privados de hegemonia e ideologia na obra de Antonio Gramsci, especialmente nos Cadernos do cárcere, valendo-se das mesmas para analisar, por meio de pesquisa documental, as atuais estratégias ideológicas das classes dominantes no fortalecimento de sua hegemonia, na refuncionalização do Estado e na condução das políticas sociais. As principais conclusões evidenciam como os governos brasileiros da era petista, apoiados em um conjunto de crenças e valores emanados da ideologia neoliberal, mantêm sua hegemonia através do consenso das classes subalternas e do apoio da classe burguesa.

Palavras-chave: Hegemonia. Aparelhos de hegemonia. Ideologia. Políticas sociais.

\section{State and Social Policies: Bourgeois hegemony and contemporary forms of domination}

Abstract: Based on theoretical research, the article reconstructs the categories of hegemony, private apparatuses of hegemony and ideology in the work of Antonio Gramsci, especially in the Prison Notebooks, using them to analyze, by means of documental research, current ideological strategies of the dominant classes for the strengthening of their hegemony, the refunctionalization of the state and execution of social policies. The main conclusions reveal how Brazil's Working Party (PT) governments have been supported by a set of beliefs and values emanating from neoliberal ideology, and have maintained their hegemony through a consensus of the subaltern classes and support from the bourgeois class.

Keywords: Hegemony. Apparatus of hegemony. Ideology. Social policies. 
Para que as coisas permaneçam como estão, é preciso que tudo mude. Giuseppe Tomasi di Lampedusa, "O Leopardo"

\section{Hegemonia e práticas de classe}

Um dos temas centrais presentes na obra de Antonio Gramsci é o conceito de hegemonia. Através dele, o pensador italiano introduziu inovações de grande relevância no estudo da política e das relações de poder a partir do século 20. Se no ensaio A questão meridional, escrito em 1926, a hegemonia é apontada como alternativa estratégica do proletariado, nos Cadernos do cárcere percebe-se uma ampliação de suas reflexões e a interface com os conceitos de ideologia e de "aparelhos privados de hegemonia". Nessa última obra, Gramsci parte de uma análise dos novos mecanismos de "dominação/direção de classe" que então se manifestavam na sociedade civil nos países de capitalismo desenvolvido (BUCI-GLUKSMANN, 1980), apontando as expressões das práticas da classe dominante. Ao analisar as diferenças estruturais nas formações sociais entre Oriente e Ocidente, Gramsci aponta como o desenvolvimento do capitalismo nos países ocidentais favorecera um maior fortalecimento das superestruturas, tornando mais difícil e complexa a conquista do poder. Ao se debruçar sobre os novos fenômenos políticos presentes no Ocidente, observa como o intenso processo de "socialização da política", adensado com o surgimento de inúmeras organizações de massa, teria alterado as relações entre sociedade civil e sociedade política, garantindo maior estabilidade ao Estado burguês.

É a partir de sua concepção ampliada de Estado que Gramsci identifica um conjunto de instituições componentes da sociedade civil, denominadas de "aparelhos privados de hegemonia", compreendendo o sistema escolar em todos os níveis, incluindo as universidades, as formas de organização da cultura (museus, bibliotecas, editoras), os meios de organização da informação em geral (jornais e revistas à época - e hoje ainda a televisão e a internet), os movimentos sociais, a organização sindical, os partidos políticos, bem como as igrejas, instituições herdadas de um modo de produção passado ${ }^{1}$. Esse conjunto de instituições presentes na sociedade civil garante sua direção política e ideológica, podendo ser tomado como critério analítico não somente para países onde a dominação da burguesia dá-se através de ditaduras, mas também naqueles em que a classe burguesa recorre ao consenso, mediante a república parlamentar.

Gramsci, de fato, havia percebido que a perpetuação da classe burguesa no poder, mais que por violência ou coerção, ocorria pela capacidade de ser "orgânica" aos centros vitais de um país, conseguindo, pelo consenso, obter o apoio e a legitimação das massas. Em sua inovadora abordagem do Estado burguês, composto pela sociedade política e pela sociedade civil, indica como as duas esferas encontram sua síntese na "supremacia", que se manifesta "como domínio" e como "direção intelectual e moral".

Hegemonia e coerção são, para Gramsci, componentes da supremacia de uma classe, coexistindo no tempo e no espaço. O fato de o Estado ser menos coercitivo e mais consensual, ou vice-versa, "depende da autonomia relativa das esferas superestruturais, da predominância de uma ou de outra", mas também do "grau de socialização da política alcançado na sociedade em questão" e da "correlação de forças entre as classes sociais que disputam a hegemonia" (GRAMSCI, 1999, p. 131). Ao retomar O príncipe, Gramsci (2000, p. 33) demarca essa dupla perspectiva referente "à natureza do Centauro maquiavélico, ferina e humana, da força e do consenso, da autoridade e da hegemonia, da violência e da civilidade, do momento individual daquele universal". Não obstante, observa-se a revalorização do "momento da hegemonia e do consenso", entendidos "como forma necessária do bloco histórico concreto" (GRAMSCI, 1999, p. 306).

É justamente a partir da análise de situações concretas que o pensador italiano elabora sua estratégia revolucionária de transição ao socialismo - a "guerra de posição" -, construída a partir da direção política e ideológica e do consenso erigido no campo da sociedade civil. A "guerra de posição", ou da revolução como processo, depende da capacidade das classes na construção de alianças e das relações de força presentes em cada conjuntura. Para Gramsci (2000, p. 24), no período posterior a 1870, com a expansão do capitalismo, modificam-se também as relações internas e internacionais do Estado, "tornando-se mais complexas e robustas". A fórmula da revolução permanente vai sendo, assim, elaborada como "hegemonia" civil e a "guerra de movimento torna-se cada vez mais guerra de posição".

$\mathrm{Na}$ análise das relações de força, Gramsci (2000, p. 36) parte do Prefácio de 1859, e, fiel ao pensamento de Marx, dele retoma dois princípios fundamentais: "o de que nenhuma sociedade se põe tarefas para cuja solução ainda não existam as condições necessárias e suficientes, ou pelo menos não estejam em vias de aparecer e se desenvolver" e, ainda, o "de que nenhuma sociedade se dissolve e pode ser substituída antes que se tenham desenvolvido todas as formas de vida implícitas em suas relações". Os princípios marxianos possibilitam ampliar a investigação em torno das relações entre estrutura e superestrutura, e 
Gramsci o faz a partir de três momentos distintos: o primeiro ligado estritamente à estrutura, o segundo às relações de forças políticas e o terceiro voltado às relações de forças militares. É no seio das relações de forças políticas que a homogeneidade, a autoconsciência e a organização dos diferentes grupos podem se desenvolver. O grau de consciência política alcançada por estes é expresso por Gramsci (2000, p. 41) também em três diferentes fases. A primeira refere-se ao momento econômico-corporativo ou "egoísticopassional"; a segunda a um momento de solidariedade de interesses entre grupos, mas ainda no campo econômico (lutas sindicais); e, por fim, a terceira remete ao momento "ético-político", de superação das necessidades corporativas e a sua universalização, sintetizada na "catarse". Esta última representa "a fase mais estritamente política", que determina, além "da unicidade dos fins econômicos e políticos, também a unidade intelectual e moral", situando a luta "num plano 'universal', criando assim a hegemonia de um grupo social fundamental sobre uma série de grupos subordinados". Temos, dessa forma, "a passagem nítida da estrutura para a esfera das superestruturas complexas", momento "em que as ideologias geradas anteriormente se transformam em 'partido', entram em confrontação", lutam, unificam-se e irradiam-se por toda a sociedade (GRAMSCI, 2000, p. 41). Vale ressaltar que tais momentos não ocorrem gradativamente, por etapas, mas inter-relacionam-se dialeticamente, dependendo de cada conjuntura e do grau de consciência política obtido pelas classes sociais.

A construção da hegemonia, no entanto, não diz respeito somente à esfera superestrutural, sendo um equívoco comum deixar-se de fora o embasamento econômico, reduzindo a disputa hegemônica aos campos cultural e ideológico. Para Gramsci (1999, p. 295), se na batalha pela hegemonia é imprescindível a valorização de uma "frente cultural como necessária, ao lado das frentes meramente econômicas e políticas", conclui-se que "se a hegemonia é ético-política, não pode deixar de ser também econômica, não pode deixar de ter seu fundamento na função decisiva que o grupo dirigente exerce no núcleo decisivo da atividade econômica" (GRAMSCI, 2000, p. 48).

Se no âmbito da superestrutura, contudo, Gramsci aponta a possibilidade das classes subalternas visualizarem as contradições que partem do mundo econômico e espraiam-se na totalidade das relações sociais, por outro lado a esfera cultural e a transformação das visões de mundo e dos modos de pensar constituemse em fatores decisivos para os que lutam por uma nova hegemonia. Assim, "a preparação ideológica das massas", o "trabalho de crítica, de penetração cultural, de permeação de ideias" fazem parte de um processo educativo, necessário ao rompimento com uma dada concepção de mundo, muitas vezes "tomada emprestada de outro grupo social, por razões de submissão e subordinação intelectual", que provoca contradições profundas no modo de ser e de agir dos sujeitos sociais (GRAMSCI, 1999, p. 97).

Destaca-se, aqui, a importância das reflexões gramscianas sobre o valor das ideologias, uma vez que, enquanto historicamente necessárias, "as ideologias [...] 'organizam' as massas humanas, formam o terreno no qual os homens se movimentam, adquirem consciência de sua posição, lutam, etc." (GRAMSCI, 1999, p. 237). Como concepção de mundo, a ideologia remete às formas de constituição da subjetividade coletiva e está presente em todos os grupos sociais, "porque em torno dela gira a 'guerra de posição' e a luta pela hegemonia que atravessa toda a sociedade" (LIGUORI, 2007, p. 86). Ganham relevância nesse contexto a função e o papel dos intelectuais orgânicos e do partido político junto às classes subalternas, "comprometidos em elaborar e difundir a visão de mundo a ser 'universalizada", com vistas a transformar os "sentimentos 'espontâneos' das massas", conferindo aos mesmos uma direção crítica e consciente (DEL ROIO, 2005, p. 172).

Para Gramsci, portanto, a hegemonia é algo que opera tanto "sobre a estrutura econômica e sobre a organização política da sociedade" como também "sobre o modo de pensar, sobre as orientações ideológicas e sobre os modos de conhecer" (GRUPPI, 1978, p. 5). Um dos pontos centrais da hegemonia é justamente a criação de um bloco ideológico, necessário à manutenção do monopólio intelectual da classe dirigente, que atrai para si as demais camadas de intelectuais para garantir tanto sua função dirigente quanto dominante, por meio de várias estratégias, especialmente a do denominado "transformismo" (PORTELLI, 1977), que envolve "um processo de cooptação das lideranças políticas e culturais das classes subalternas", excluindo-as "de todo efetivo protagonismo nos processos de transformação social" (COUTINHO, 2010, p. 38). O transformismo, aliado ao consenso passivo, pode ser traduzido na concepção gramsciana da "pequena política", que leva as massas a aceitarem a ordem presente como "algo natural", sem perspectivas de transformação.

Conforme assevera Coutinho (2010, p. 30), "uma relação de hegemonia é estabelecida quando um conjunto de crenças e valores se enraíza no senso comum, naquela concepção de mundo [...] 'bizarra e heteróclita", frequentemente contraditória, que orienta "o pensamento e a ação de grandes massas de homens e mulheres". É exatamente neste senso comum que se manifestam determinados valores e formas de pensar que "asseguram a reprodução do capitalismo" contemporâneo e se expressam na realidade atual através de práticas concretas levadas a efeito por governos, organismos internacionais e outras instituições mediante as políticas neoliberais, conforme veremos a seguir. 


\section{Estado, políticas sociais e hegemonia burguesa}

As repercussões das crises cíclicas do capital, desencadeadas desde a década de 1970, bem como seu aprofundamento entre 2007 e 2008, não atingiram apenas a esfera econômica, mas serviram como "peça ideológica fundamental" na legitimação das novas iniciativas de refuncionalização do Estado e sua centralidade no apoio à tendência expansiva do capital (THERBORN, 2012). O thatcherismo na Inglaterra, o reaganismo nos Estados Unidos, o pinochismo no Chile, por exemplo, encarregaram-se de conferir visibilidade à doutrina neoliberal e ao projeto "intelectual e moral" da burguesia, alicerçado em um amplo programa de privatizações e na redução da "intervenção" estatal, especialmente nos aparatos da Seguridade Social e nas conquistas do Welfare State. O empobrecimento brutal de extensas camadas da classe trabalhadora, derivado das medidas tomadas no contexto das crises, tornou necessário rever e ampliar as formas de intervenção do Estado na questão social, ainda que mascaradas "por uma retórica sobre a liberdade individual, autonomia, responsabilidade pessoal" (HARVEY, 2011, p. 16). Em sintonia com os interesses burgueses, os organismos internacionais e os Estados buscaram sugerir alternativas no âmbito das políticas sociais, preservando incólumes os princípios básicos do mercado. A reforma das instituições, o aumento de redes de seguridade social, as metas de superação da pobreza e os pactos anticorrupção foram algumas das medidas elencadas no Pós-Consenso de Washington, assumidas nos anos 1990 pela maioria dos países, especialmente na América Latina.

O colapso financeiro internacional de 2008, no entanto, levou o Banco Internacional de Reconstrução e Desenvolvimento (BIRD) e as demais agências internacionais a retomar os princípios "do auge do neoliberalismo", especialmente no campo das políticas e dos direitos sociais. Assim, em 2009, "os chefes dos organismos internacionais das Nações Unidas lançaram oficialmente a Iniciativa Piso de Proteção Social (PPS), coordenada pela Organização Internacional do Trabalho (OIT) e pela Organização Mundial da Saúde (OMS), como uma das iniciativas conjuntas para enfrentar os efeitos da crise" (OIT, 2009). Liderada pela ex-presidente chilena Michelle Bachelet, a proposta orienta-se na "gestão social do risco" (HOLZMANN; JORGENSEN, 2000), transferindo recursos financeiros aos pobres a fim de capacitá-los a enfrentar incertezas, acessando diretamente o mercado. Programas de transferências de renda, ações como microcrédito e outras voltadas ao "empreendedorismo" são recomendadas como forma de assegurar alguma renda para que os grupos mais vulneráveis possam adquirir os bens e serviços sociais de que necessitem. A lógica privatizante resta implícita nesta concepção de "Seguro Social", constituindo-se na "antítese do conceito de Seguridade Social", surgida pela necessidade de se enfrentar a situação dramática vivida por muitos países, apresentando-se como a "nova embalagem para a focalização" (FAGNANI, 2011, p. 15).

Tal iniciativa ganhou impulso após a crise de 2008-2009, sendo referendada por uma ampla coalizão global que reúne as principais lideranças mundiais (G-8 e G-20), FMI, BIRD, ONGs e 19 agências da Organização das Nações Unidas (ONU), que formalizaram o chamado "Pacto Mundial para o Emprego". Além desse documento, o PPS é inspirado nas experiências dos programas de transferência de renda Oportunidades, do México, do Chile Solidário e, especialmente, o Programa Bolsa Família, do Brasil (PBF), sendo este considerado pelo BIRD um "case internacional de sucesso" e "um dos programas de assistência social de maior envergadura no mundo". Arquiteta-se, assim, em âmbito mundial, o convencimento acerca das "virtudes" dos programas de transferência de renda focalizados às camadas mais pobres dentre os pobres, reduzindo-se a esta perspectiva o sistema de proteção social, desfigurando-se o conceito clássico de Seguridade Social. Este consenso global arquitetado pelas agências internacionais reforça a hegemonia do BIRD e o retrocesso da OIT, que desde a década de 1950 difundiu, através de vários documentos, a defesa da Seguridade Social como um direito universal. A agenda liberalizante segue, portanto, "apoiada na focalização dos mais pobres, na privatização de bens e serviços segundo a lógica do mercado, na supressão de direitos trabalhistas e sindicais e na valorização do capital humano" (FAGNANI, 2011, p. 2).

A dominação do capitalismo desorganizado e a hegemonia do capital financeiro têm provocado índices cada vez mais desiguais na distribuição de renda no mundo. Nas últimas duas décadas, “os $20 \%$ mais ricos da população mundial receberam mais de $70 \%$ da renda global, enquanto os $20 \%$ mais pobres receberam apenas cerca de 2\%". Também na Europa, estudos recentes divulgados pela Organização para Cooperação e Desenvolvimento Econômico (OCDE) indicam que a distribuição de renda piorou em vários países entre 1985 e 2008 , sendo que a desigualdade atingiu o seu nível mais alto em $50 \operatorname{anos}^{2}$ (OIT, 2011).

As duras propostas dos organismos internacionais foram acolhidas pelos governos brasileiros, desde Fernando Henrique Cardoso, passando à era petista, atenuadas por políticas sociais compensatórias. Ao assumir a presidência em 2003, Luiz Inácio Lula da Silva destacou como prioridade a "erradicação da pobreza", a ser enfrentada através dos programas de transferência de renda, entendidos como "necessários" para garantir o poder aquisitivo das famílias, reduzir sua pressão sobre o mercado de trabalho e, ao mesmo tempo, favorecer o consumo de massa. Tais programas combinaram políticas universais focalizadas no combate à pobreza 
extrema, tendo o PBF como principal estratégia, atendendo, entre 2003 e 2009, cerca de 12,4 milhões de famílias, sendo meta do governo Dilma Roussef (2011 a 2014) beneficiar 16 milhões de famílias até 2014.

A intensificação do discurso do combate à pobreza e do papel do Estado como propulsor do desenvolvimento econômico, combinado ao desenvolvimento social, levou o atual governo a ampliar o PBF e criar novos programas sociais, destacando-se o Programa Brasil Sem Miséria, articulado igualmente pela lógica de acesso ao consumo e a busca de equidade social. Um dos objetivos do programa é avançar na integração do PBF a outras políticas sociais ${ }^{3}$, destacando-se o Minha Casa, Minha Vida, um programa vinculado aos preceitos do mercado imobiliário - e não à perspectiva do direito à habitação.

\section{Na conjuntura presente, $\mathrm{o}$} Estado exerce, por conseguinte, sua tarefa educativa, não para a formação do "homem coletivo", mas para o "conformismo social" ...

Nos oito anos do governo Lula consolidaram-se, portanto, as premissas neoliberais, com o apoio do capital financeiro, do consenso ativo das principais organizações do mundo do trabalho e do consenso passivo das massas trabalhadoras desorganizadas, por meio das políticas sociais compensatórias. Se, aparentemente, o binômio "crescimento econômico com justiça social" chamaria a atenção para aspectos inovadores, pode-se dizer que na era Lula este desenvolvimentismo não rompe com as premissas neoliberais, revelando-se um "reformismo quase sem reformas", na expressão de Arcary. Embora nas gestões do PT tenha ocorrido a redução do desemprego - ainda que a taxas menores das verificadas ao longo dos anos noventa -, garantindo uma elevação real do salário mínimo acima da inflação, o aumento da mobilidade social e a ampliação dos benefícios do PBF (ARCARY, 2013), tais alterações, contudo, pouco modificaram o quadro social, uma vez não terem ocorrido mudanças estruturais na sociedade brasileira, sendo exemplar o sistema tributário e seu caráter regressivo, que incide sobre o consumo de bens e salários, mas não sobre as grandes fortunas (COSTA, 2012). Se o retrocesso da pobreza absoluta, com os programas sociais compensatórios, é de inequívoca importância, pouco se alterou na "concentração de renda", persistindo ainda um alto índice de desigualdade social.

A avaliação do Banco Mundial (2011) sobre o Brasil, apresentada no documento Estratégia de Parceria de País (Country Partnership Strategy - CPS), para o resultado do período 2008-2011 e para as metas do período 2012-2015, no entanto, é altamente positiva. Nesse documento, o BIRD avalia que na última década o Brasil obteve "progresso econômico e social admirável e está a caminho de um crescimento inclusivo e ambientalmente sustentável". Indica-se que, desde o governo Lula, 22 milhões de habitantes deixaram a situação de pobreza, e a economia estável permitiu "superar com êxito a crise econômica global de 2008-2009". Essa avaliação positiva prossegue no governo Dilma Rousseff, com "metas sociais e econômicas ambiciosas para os próximos anos", tais como aumentar o potencial de crescimento do Brasil acima dos atuais $4 \%$ a 4,5\%, por meio de maiores investimentos, elevação da poupança pública e investimentos em infraestrutura através dos Programas de Aceleração do Crescimento I e II (PAC I e PAC II).

Tais investimentos em áreas de saneamento, habitação, transporte e recursos hídricos ampliam "enormemente o poder do capital financeiro, do agronegócio, da mineração, do setor energético e da construção civil", frações da burguesia que mais se têm beneficiado no governo petista. Os projetos em tela fortalecem as burguesias internas e externas, pelas facilidades oferecidas na exploração de terras, florestas, mananciais de água, reservas minerais, bem como de mão de obra (PINASSI, 2013). Os subsídios ao grande capital, industrial e financeiro, também têm ocorrido através dos recursos do Banco Nacional de Desenvolvimento Econômico e Social (Bndes), que financiará 80\% dos projetos para a Copa de 2014 e para as Olimpíadas de 2016, beneficiando bancos e empresas através de privatizações (COGGIOLA, 2013) de rodovias, portos e aeroportos, sob a forma de parcerias público-privadas. Estas são as camadas de classe que aderem ao Estado e que não concebem "a sociedade política para além do âmbito de seu 'particular"” (GRAMSCI, 2000, p. 127). Assim, o projeto de governo do PT agradou tanto o capital em geral, especialmente o setor financeiro, e, ao mesmo tempo, os organismos internacionais e as camadas mais pobres da população.

No tocante à educação superior, ao invés do reforço no orçamento das universidades federais, inchadas pela desmesurada ampliação das vagas, foi criado no governo Lula o Programa Universidade Para Todos (Prouni), transferindo grande soma de recursos para as universidades privadas. Na área da saúde, os gastos privados têm superado os gastos públicos e o Sistema Único de Saúde (SUS), com a promulgação da Emenda Constitucional n. 29, corre o risco de restringir-se basicamente a duas funções: "a assistência de pessoas pobres e a cobertura de demandas negadas pelas operadoras privadas" (SAMPAIO JÚNIOR, 2013). Outras iniciativas estão em curso, como o implemento da Empresa Brasileira de Serviços Hospitala- 
res S.A. (Ebserh), instituição pública de personalidade jurídica privada, isenta de controle social, contrariamente ao preconizado pelo SUS. A Ebserh poderá administrar tanto os hospitais universitários como qualquer unidade hospitalar no âmbito do SUS, por meio de contrato de gestão. Em relação à saúde pública, o BIRD enfatiza a necessidade de se aumentar o foco nas parcerias público-privadas (PPPs), em prestadores de serviços de saúde e diagnósticos criados para servir à população de rendas média e baixa, além de ampliar a participação das organizações da sociedade civil (OSC).

A difícil situação em que chegou a saúde não se deve a problemas de gestão da coisa pública, como se convencionou vaticinar, discurso que promove mais brechas à privatização. As razões têm seu ethos nas medidas neoliberais, que desde os anos 1990 colocaram em cheque as políticas sociais universalistas, incompatíveis com a política macroeconômica e as restrições do Estado na área social. Conforme aponta Costa (2013), "ao tempo em que hoje 30\% da população aderiu aos planos privados, os recursos públicos destinados para o SUS mínguam a míseros 300 dólares per capita/ano, constrangendo o sistema a uma péssima avaliação e satisfação popular", fortalecendo "um projeto anti-SUS, antidireito à saúde, antidireitos sociais, e, de sobra, as empresas da saúde comparecem nos processos eleitorais com polpudas contribuições que, ao fim e ao cabo, não resultam gratuitas".

Também a reforma agrária sofreu poucas alterações, sendo praticamente substituída pelo Programa Nacional de Fortalecimento da Agricultura Familiar (Pronaf). A promessa de uma gestão comprometida com os propósitos da reforma agrária e de um desenvolvimento com distribuição de renda trouxe novas esperanças para os movimentos populares. Não obstante, com o passar dos anos percebeu-se que a superação da concentração da terra no Brasil não figurava mais entre os planos petistas, passando a reforma agrária a ser relacionada à desapropriação das terras consideradas improdutivas e ao fomento do desenvolvimento rural. Nota-se que, apesar dos crescentes investimentos realizados no Pronaf, os recursos destinados à grande produção agrícola e as monoculturas configuraram-se consideravelmente maiores, consolidando nossa vocação ao latifúndio.

Além disso, conforme indica Pochmann (2012), "o mercado de trabalho registrou pouco dinamismo no emprego industrial e forte crescimento na área de serviços, com elevado grau de rotatividade dos trabalhadores". A perspectiva atual no mundo do trabalho "é a de constituir uma classe trabalhadora do capital e não apenas para o capital" (DIAS, 2006, p. 199), sendo exemplares o Programa Nacional de Acesso à Escola Técnica (Pronatec) e as parcerias com o sistema S (Sesi, Senac, Senai).

Segundo dados da Auditoria Cidadã da Dívida (2012), em 2011 foram utilizados 45\% dos recursos somente para o pagamento dos juros da dívida, em contraposição a 4,07\% para a saúde, 2,99\% para a educação, 2,85\% para a assistência social, 2,29\% para as políticas de trabalho, $0,12 \%$ para a reforma agrária e 0,41 $\%$ para a segurança pública. Comparado aos dados acima, o PBF corresponde a um orçamento ínfimo: cerca de $0,4 \%$ do PIB, contra os $45 \%$ dos juros da dívida pública.

Frente à situação de vulnerabilidade externa e dos possíveis impactos da crise mundial, mais uma vez o governo recorreu ao "receituário neoliberal mais duro, evidenciando seu compromisso orgânico com os interesses do grande capital, particularmente do capital financeiro, em detrimento das classes trabalhadoras", pois o corte de despesas tem incidido prioritariamente sobre a área social. Em fevereiro de 2011, com o intuito de proteger a economia da crise mundial, o governo anunciou um corte de 50 bilhões de reais, e outro em 2012, desta vez de 55 bilhões de reais, nos gastos em investimentos e, principalmente, em custeio, que abrange o funcionalismo público, as despesas previdenciárias, o seguro desemprego, o abono salarial, a saúde e a segurança pública, dentre outros (PORTAL BRASIL, 2011).

Ao mesmo tempo em que ocorria a ampliação da política de assistência social, com os programas focalizados de combate à pobreza, ampliava-se o investimento em empreendedorismo, empregabilidade, inserção social, responsabilidade social, práticas reforçadoras da ideologia da "colaboração entre classes". Tais ações abarcam inúmeros projetos, especialmente nas áreas de educação e assistência social, envolvendo, em sua maioria, grandes grupos capitalistas, fundações privadas, ONGs e entidades empresariais, contando com apoio e subsídios governamentais (MATTOS, 2013). Em 2010, segundo dados da ABONG, havia no Brasil 290,7 mil fundações privadas e associações sem fins lucrativos (Fasfil) ${ }^{4}$, ampliando-se, assim, os aparelhos privados de hegemonia do grande capital, incluindo os tradicionais meios de comunicação e de organização da cultura, que "se empenham por difundir a "nova pedagogia da hegemonia" (NEVES, 2005).

As concessões ao grande capital, contudo, não se restringem apenas às políticas a seu favor, "querem também políticas contra a classe trabalhadora. Mais exatamente, querem reverter o conjunto de conquistas sociais e econômicas que a classe trabalhadora obteve ao longo dos dez anos de Lula e Dilma" (POMAR, 2013). Há que se recordar, também, que no início da gestão Lula, o primeiro embate político importante do governo não foi contra algum setor das classes dominantes, mas contra o funcionalismo público, com a implementação da reforma da Previdência Social, medida utilizada a fim de "acalmar os mercados" e ganhar a confiança. 
Conforme analisa Pinheiro (2013, p. 3), o PT, a partir do transformismo, desenvolveu "um politicismo policlassista para fazer mediações e disputas no espaço institucional da ordem e não contra a ordem do capital". A instauração de um sistema de colaboração classista ficou patente no Fórum Nacional do Trabalho, onde a bancada dos empregadores e a dos trabalhadores firmaram um consenso em torno da questão do direito de greve nos chamados "serviços essenciais", com vistas à limitação do direito de greve dos servidores públicos.

Aliado às forças mais conservadoras da política brasileira, o governo "age em conjunto com as várias frações de classe da burguesia" não apenas para atender os interesses dessa classe, mas também para enfrentar os trabalhadores. Além disso, "a política do neodesenvolvimentismo do bloco monopolista interno procura derrotar os lutadores em confronto, do ponto de vista estratégico, para cooptá-los do ponto de vista tático", bloqueando a luta na defesa dos direitos, na garantia de condições de trabalho, melhoria salarial e mobilização democrática na sociedade brasileira (COGGIOLA, 2013).

O Estado representa, assim, "todo o complexo de atividades práticas e teóricas com os quais a classe dirigente não só justifica e mantém o seu domínio, mas consegue obter o consenso ativo dos governados" (GRAMSCI, 2000, p. 331), incorporando-os à esfera estatal e suprimindo suas tentativas de autonomia. Esse processo de transformismo "representa brutalmente o escoamento gradual das energias sociais e políticas alternativas", deslocando a luta de classes para a direita, além de favorecer "a passividade das massas trabalhadoras desorganizadas diante dos efeitos da crise econômica e social, de um lado, e a criação de uma situação política e ideológica francamente hostil às reivindicações democráticas e populares" (BARATA, 2011, p. 34). Além disso, a cooptação de dirigentes partidários, sindicais e populares pelo governo, alojando-os "na estrutura burocrática do Estado", desmobilizou "o movimento sindical e os movimentos sociais, com graves consequências para a esquerda" (MACIEL, 2013). A atual hegemonia burguesa é portadora de uma cultura política de esvaziamento, que relega "a vontade popular às engrenagens puramente burocrático-institucionais da máquina eleitoral", obstaculiza a formação do consenso ativo e direto e manipula, "para fins conservadores", os "impulsos inovadores" das classes subalternas (BARATA, 2011, p. 126).

Enquanto para a hegemonia de uma classe, que tende a ocultar o antagonismo dos interesses, é suficiente obter um consenso passivo e indireto - e esta se constitui na forma normal do consenso político nos regimes democrático-burgueses ou autoritários -, na perspectiva da hegemonia do proletariado "é uma questão vital" escreve Gramsci (2000, p. 333) - "não o consenso passivo e indireto, mas o consenso ativo e direto, ou seja, a participação dos indivíduos, mesmo que isto provoque uma aparência de desagregação e de tumulto".

As classes dominantes buscam construir, com o discurso do crescimento econômico com justiça social, "uma linguagem aceitável e passível de ser falada por todas as classes" (DIAS, 2006, p. 13). Ideias universalistas como justiça, equidade, liberdade, democracia, cidadania, participação, direitos, predominam hoje no eixo estruturante das políticas sociais, e a "questão da política parece ter perdido sua aspereza e se transformado na gestão e formulação de pactos sociais" (DIAS, 2006, p. 16), ou seja, da "pequena política", com programas que fortalecem "o desinteresse em relação à participação política dos indivíduos" (BARATA, 2011, p. 36). Esse discurso ideológico passa a ser a linguagem cotidiana das classes subalternas, cujo saber e formas de pensar definem-se a partir de sua inserção subordinada na estrutura social. A necessidade de buscar respostas imediatas aos problemas cotidianos leva tais classes a responder de forma fragmentária, não alcançando a construção de saberes que se contraponham ao discurso dos dominantes. Desse modo, "os saberes/práticas dos dominantes ditam os ritmos e as formas de todo saber constituído e constituível", pois, "para as classes dominantes basta a reprodução pura e simples de suas práticas. Estas são pensadas como forma técnica da sua racionalidade classista" (DIAS, 2006, p. 31).

$\mathrm{Na}$ conjuntura presente, o Estado exerce, por conseguinte, sua tarefa educativa, não para a formação do "homem coletivo", mas para o "conformismo social", para a coesão e a integração, adequando "as massas populares às necessidades do contínuo desenvolvimento do aparelho econômico de produção", através do consenso passivo e da colaboração em torno de sua hegemonia (GRAMSCI, 2000, p. 23). Estas formas de pensar da burguesia têm na atualidade uma eficácia direta sobre as classes subalternas, uma vez que os valores ideológicos e políticos "influem sobre as massas populares como força política externa, como elemento de força coesiva das classes dirigentes", atuando como "fermento vital de transformação interna do que as massas pensam, embrionária e caoticamente, sobre o mundo e a vida" (GRAMSCI, 1999, p. 114-115).

As primeiras aproximações da pesquisa em tela permitem indicar a fecundidade das categorias gramscianas na análise da realidade atual, evidenciando que nestes tempos de continuidade das contrarreformas, de refuncionalização do Estado e das políticas sociais, predominam a "hegemonia da pequena política" e o "consentimento passivo", aceitando-se a ordem como natural e imutável. Os Estados nacionais e as organizações internacionais reconhecem a necessidade de atenção à "questão social", porém com políticas assistencialistas, que não alteram a essência da ordem do capital. Reafirma-se, neste cenário, a importância do 
acúmulo de forças e a (re)organização dos institutos coletivos da classe trabalhadora na universalização das demandas, como essenciais e imprescindíveis ao enfrentamento da hegemonia burguesa e à busca de caminhos de subversão à ordem vigente, com vistas à construção de um projeto civilizatório que somente poderá emergir a partir da incontestável pressão vinda dos "de baixo".

\section{Referências}

ARCARY, V. Dez anos de governos de coalizão dirigidos pelo PT. 2013. Disponível em: <http://marxismo21.org/10-anos-de-governosdo-pt-natureza-de-classes-e-neoliberalismo>. Acesso em: 15 jul. 2013.

AUDITORIA CIDADÃ DA DÍVIDA. 2012. Disponível em: 〈http://www.auditoriacidada.org.br/wp-content/uploads/2012/04/ Numerosdivida.pdf>. Acesso em: 12 ago. 2013.

BANCO MUNDIAL. Estratégia de parceria de país para a República Federativa do Brasil. Exercícios fiscais 2012 a 2015. Relatório n. 63731-BR. 21 set. 2011.

BARATTA, G. Antonio Gramsci em contraponto. São Paulo: Unesp, 2011.

BUCI-GLUCKSMANN, C. Gramsci e o Estado. Tradução de Angelina Peralva. Rio de Janeiro: Paz e Terra, 1980.

COGGIOLA, O. 10 anos de governo do PT - Frente Popular. 2013. Disponível em: <http://marxismo21.org/10-anos-de-governos-dopt-natureza-de-classes-e-neoliberalismo>. Acesso em: 15 jul. 2013.

COSTA, L. C. Classe média brasileira: há um novo cenário? 2012. Disponível em: 〈www.políticasocial.net.br〉. Acesso em: 10 ago. 2013

COSTA, A. M. É o povo, que pressionando, pode mudar a saúde no Brasil. 2013. Disponível em: <http://www.politicasocial.net.br/ index.php/salamidia/234-sala-anacosta.html>. Acesso em: 9 ago. 2013.

COUTINHO, C. N. A hegemonia da pequena política. In: OLIVEIRA, F.; BRAGA, R.; RIZEK, C. (Org.). Hegemonia às avessas. São Paulo: Boitempo, 2010.

DEL ROIO, M. Os prismas de Gramsci: a fórmula política da frente única (1919-1926). São Paulo: Xamã/IAP/Fapesp, 2005.

DIAS, E. Política brasileira: embate de projetos hegemônicos. São Paulo: Sundermann, 2006.

FAGNANI, E. Análises e propostas. Seguridade Social: a experiência brasileira e o debate internacional. 2011. Disponível em: <http:// library.fes.de/pdf-files/bueros/brasilien/09533.pdf >. Acesso em: 12 ago. 2013.

GRAMSCI, A. Cadernos do cárcere. Tradução de Carlos Nelson Coutinho com a colaboração de Luiz Sergio Henriques e Marco Aurélio Nogueira. Rio de Janeiro: Civilização Brasileira, 1999. (v. 1).

Cadernos do cárcere. Tradução de Carlos Nelson Coutinho com a colaboração de Luiz Sergio Henriques e Marco Aurélio Nogueira. Rio de Janeiro: Editora Civilização Brasileira, 2000. (v. 2).

. Cadernos do cárcere. Tradução de Carlos Nelson Coutinho com a colaboração de Luiz Sergio Henriques e Marco Aurélio Nogueira. Rio de Janeiro: Civilização Brasileira, 2000. (v. 3).

GRUPPI, L. 1978. O conceito de hegemonia em Gramsci. Rio de Janeiro: Graal.

HARVEY, D. O enigma do capital. Tradução de João Alexandre Peschanski. São Paulo: Boitempo, 2011.

HOLZMANN, R.; JORGENSEN, S. Social Risk Management: a new conceptual framework for social protection and beyond. World bank, Human Development Network. Social Protection Discussion Paper Series. 2000.

LIGUORI, G. Roteiros para Gramsci. Tradição de Luiz Sérgio Henriques. Rio de Janeiro: UFRJ, 2007.

MACIEL, D. De Lula à Dilma Roussef: crise econômica, hegemonia neoliberal e regressão política. 2013. Disponível em: <http:// marxismo21.org/10-anos-de-governos-do-pt-natureza-de-classes-e-neoliberalismo >. Acesso em: 15 jul. 2013.

MATTOS, M. B.Dez anos de governo petista e a consolidação da dominação burguesa no Brasil. 2013. Disponível em: <http:// marxismo21.org/10-anos-de-governos-do-pt-natureza-de-classes-e-neoliberalismo>. Acesso em: 15 jul. 2013.

NEVES, L. M. W. A nova pedagogia da hegemonia: estratégias do capital para educar o consenso. São Paulo: Xamã, 2005.

OIT-Organização Internacional do Trabalho. Iniciativa del Piso de Protección Social de las Naciones Unidas. Sexta Iniciativa de la JJE em respuesta a la crisis financiera económica y global y su impacto en el trabajo del sistema de lãs Naciones Unidas, 2009.

. Piso de Proteção Social para uma Globalização Equitativa e Inclusiva. Relatório do Grupo Consultivo presidido por Michelle Bachelet, constituído pela OIT com a colaboração da OMS. Genebra, 2011.

PINASSI, M. O. O PT e os trabalhadores brasileiros: lutas, conciliação, desregulamentação. 2013. Disponível em: <http://marxismo21.org/ 10-anos-de-governos-do-pt-natureza-de-classes-e-neoliberalismo>. Acesso em: 15 jul. 2013.

PINHEIRO, M. O governo petista como operador político da burguesia no Brasil. 2013. Disponível em: <http://marxismo21.org/10anos-de-governos-do-pt-natureza-de-classes-e-neoliberalismo>. Acesso em: 15 jul. 2013.

POCHMANN, M. Nova classe média? São Paulo: Boitempo, 2012.

POMAR, V. Os dez anos de governo do PT: caráter de classe e relação com política neoliberal. 2013. Disponível em: <http:// marxismo21.org/10-anos-de-governos-do-pt-natureza-de-classes-e-neoliberalismo>. Acesso em: 15 jul. 2013.

PORTAL BRASIL. Economia, 2011. Disponível em: <http://www.brasil.gov.br/sobre/economia〉. Acesso em: 15 jun. 2013.

PORTELLI, H. Gramsci e o bloco histórico. Tradução de Angelina Peralva. Rio de Janeiro: Paz e Terra, 1977. 
SAMPAIO JÚNIOR, P. de A. A opção do PT. 2013. Disponível em: <http://marxismo21.org/10-anos-de-governos-do-pt-natureza-declasses-e-neoliberalismo>. Acesso em: 15 jul. 2013.

THERBORN, G. Do marxismo ao pós-marxismo? Tradução de Rodrigo Nobile. São Paulo: Boitempo, 2012.

\section{Notas}

1 Vale ressaltar que essa perspectiva institucional presente nas reflexões de Gramsci não se confunde com a perspectiva weberiana, uma vez que os aparelhos de hegemonia são atravessados pela luta de classes.

2 Dados da OIT (2011 - A: XXIII) indicam que cerca de 5,1 bilhões de pessoas, 75\% da população mundial, não estão cobertos por um sistema adequado de seguridade social, e 1,4 bilhão de pessoas vivem com menos de US\$1.25 por dia (BIRD). Trinta e oito por cento da população global (2,6 bilhões de pessoas) não tem acesso a saneamento básico e 884 milhões de pessoas não dispõem de fontes adequadas de água potável (UNHABITAT); 925 milhões sofrem de fome crônica (FAO); cerca de 9 milhões de crianças com menos de 5 anos de idade morrem todos os anos vítimas de doenças evitáveis (UNICEF e OMS); 150 milhões de pessoas sofrem anualmente catástrofes financeiras e 100 milhões de pessoas são empurradas abaixo da linha de pobreza quando obrigadas a pagar pelos cuidados de saúde (OMS)”.

3 Destacam-se: SUS, na área da saúde; Sistema Público de Trabalho, Emprego e Renda; Programa Nacional de Acesso à Escola Técnica; Programa Nacional de Inclusão de Jovens; Programas de habitaçãoe saneamento que vêm sendo desenvolvidos no âmbito do Programa de Aceleração do Crescimento; Minha Casa, Minha Vida; Benefício de Prestação Continuada; Programa de Erradicação do Trabalho Infantil; Programa Brasil Carinhoso; Programa Luz para Todos; Programa Nacional de Inclusão de Jovens (urbano, campo e trabalhador); Política Nacional de Assistência Estudantil; Programa Universidade para Todos (Prouni); Fundo de Financiamento Estudantil (FIES).

4 Além disso, programas como o Criança Esperança, criado em 1986 pela Rede Globo, que abrange 86,33\% dos 5,564 municípios brasileiros, têm como objetivo "aumentar a conscientização sobre os direitos das crianças e motivá-los a ter a esperança de um futuro melhor". Desde sua criação, o programa conta com aproximadamente cinco mil projetos e atinge mais de quatro milhões de crianças e jovens de todo o Brasil. OprojetoAmigos da Escola, também criado pela Rede Globo tem como objetivo atuar junto ao ensino público, através do serviço voluntário, contando com mais de 30 mil escolas participantes. São números que revelamo "tamanho do aparato mobilizado para transmitir aos subalternos os valores adequados à adaptação a uma ordem produtiva capitalista baseada na ampliação da expropriação e na intensificação da exploração da classe trabalhadora" (MATTOS, 2013).

\section{Ivete Simionatto}

ivetesimionatto@hotmail.com

Pós-Doutorado no European University Institute (EUI), Itália

Doutora em Serviço Social pela Pontifícia Universidade Católica de São Paulo (PUC/SP)

Professora no Curso de Serviço Social e no Programa de Pós-Graduação em Serviço Social (PPGSS), na Universidade Federal de Santa Catarina (UFSC)

\section{Carolina Rodrigues Costa}

carol_costa2@yahoo.com.br

Mestranda do Programa de Pós-Graduação em Serviço Social da UFSC

\section{UFSC - PPGSS}

Campus Universitário Reitor João David Ferreira Lima

Trindade

Florianópolis - Santa Catarina - Brasil

CEP: 88040-970 